\title{
Evaporation estimation from meteorological parameters using multiple linear regression model
}

\section{NEERAJ KUMAR, GAURANG JOSHI, ROHIT KUMAR AND PANKAJ KUMAR}

Received : 22.07.2017; Revised : 23.08.2017; Accepted : 09.09.2017

See end of the Paper for authors' affiliation

Correspondence to :

NEERAJ KUMAR

Department of Soil and Water Conservation Engineering,

College of Technology,

Govind Ballabh Pant

University of Agriculture and

Technology, Pantnagar, U.S.

NAGAR (UTTARAKHAND),

INDIA

Email : neerajkumarsaini.126@

gmail. com
-ABSTRACT : Evaporation is one of the main elements affecting water storage and temperature in the hydrological cycle and it plays an important role in evaluation of water availability. Considering the difficulty involved in direct method of evaporation estimation and limitation of empirical methods, an attempt has been made to estimate evaporation by multiple linear regression with the aid of gamma test (GT). The data of meteorological parameters viz., average temperature $\left(\mathrm{T}_{\text {avg }}\right)$, wind speed $(\mathrm{W})$, average relative humidity $\left(\mathrm{Rh}_{\text {avg }}\right)$ and sunshine hours $(\mathrm{S})$ were used as input parameters and evaporation was considered as output parameter. The performance of developed model was evaluated in terms of mean squared error (MSE) and correlation co-efficient (r). In developed model, MSE was found to be 1.13 and 0.92 in training and testing phase, respectively. The model demonstrated good values of correlation co-efficient, respectively as 0.91 and 0.95 for training and testing period indicating the suitability of model to estimate the evaporation.

- KEY WORDS : Evaporation, Meteorological parameters, MLR, Gamma test

- HOW TO CITE THIS PAPER : Kumar, Neeraj, Joshi, Gaurang, Kumar, Rohit and Kumar, Pankaj (2017). Evaporation estimation from meteorological parameters using multiple linear regression model. Internat. J. Agric. Engg., 10(2) : 503-507, DOI: 10.15740/HAS/IJAE/10.2/503-507. 